\title{
Facing Off: From Abstraction to Diffraction in Hito Steyerl's Abstract (2012)
}

Lawrence Alexander

DOI: $10.15664 /$ fcj.v18i1.2247

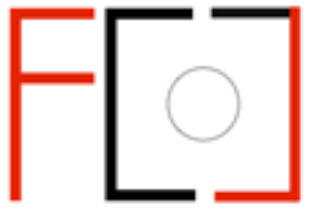

Frames Cinema Journal ISSN 2053-8812

Issue 18 (Jun 2021)

http://www.framescinemajournal.com

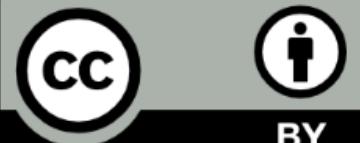




\title{
Facing Off: From Abstraction to Diffraction in Hito Steyerl's Abstract (2012)
}

\author{
Lawrence Alexander
}

\section{Introduction}

The video art of the German moving image practitioner and writer Hito Steyerl enlists the smartphone (invariably an iPhone) to perform multiple, often contradictory tasks. Steyerl's artistic practice manipulates the multi-functionality of the smartphone and cites its radical transformation of everyday practices of perception, navigation, and communication, while also foregrounding the obdurate materiality and artefactual quality of the device as a concrete object and conspicuous prop. This article considers the role of the smartphone as a "signature artefact", both object and tool of media archaeological investigation, simultaneously marking obsolescence and novelty, singularity and seriality. ${ }^{1}$ I analyse the smartphone as an interface that mediates the gesture of the artist's face, hand, and eye, and circulates between disparate spatio-temporal realities. This model is instructive as a means to understand the smartphone as window and plane, frame and screen, transparent and opaque. Thus, the smartphone intersects with a constellation of orientational, perceptual, and ontological binaries that are both reinforced and exceeded by the device, disrupting the abstraction of linear perspective to activate forms of circuitous intensity.

This analysis centres on a work that features the smartphone more prominently than any other in Steyerl's oeuvre: Abstract (2012). This seven-minute, two-channel video evokes the conceit of a core unit of cinematic "grammar" - shot-countershot - to enact a face-off between Berlin's “empty centre", around the Brandenburg Gate, and the site in Eastern Turkey of the alleged murder of Steyerl's friend, Andrea Wolf, by the Turkish military in $1998 .{ }^{2}$ On the one hand, the reverse function of the phone camera ostensibly aligns with the directional opposition of shot-countershot. At the same time, the orientation of the camera in three-dimensional space 
exercises a more expanded, free-floating mobility between - and beyond - the binary constraints of shot-countershot, portrait and landscape orientation, and frontal and lateral perspectives. This article explores how the compositional logic of Abstract moves across and between the various organisational architectures of the smartphone, the built environment, and filmic space: windows, doors, and gateways; faces and façades. I read the central function of the iPhone as manipulation and multiplication of the spatio-temporal ordering of cinematic editing it purports to imitate: distorting and diffracting the linear perspective of shotcountershot and "circling back" to the headquarters of aerospace and arms company Lockheed Martin in view of the Brandenburg Gate. I contend it is this multiplicity and flexibility, paradoxically afforded by the obdurate materiality of the iPhone, that constructs the evidentiary grounds to simultaneously locate and interrogate the violence of the military-industrial complex - that which would remain faceless, unseen, abstract.

\section{Smartphone as Signature Artefact}

Adam Greenfield, in Radical Technologies: The Design of Everyday Life, describes the smartphone straightforwardly as "the signature artefact of our age", and the "universal, all-butindispensable mediator of everyday life." ${ }^{3}$ The smartphone also bears something of a signature character in Steyerl's installations and video works, including - in addition to Abstract - How Not to Be Seen: A Fucking Didactic Educational .MOV File (2013), and Liquidity Inc. (2014). More recently, in Power Plants (2019), an installation at London's Serpentine Sackler Gallery, the smartphone became integral to the user's engagement with an exhibition that included predictive video sculptures generated by neural networks. In addition, a downloadable app, "Actual Reality OS", allowed visitors to access data visualisation models displayed in augmented reality on the gallery building's external architecture. Inside, iPads were situated 
throughout the installation space, accessible to users who utilised them to see imagined quotations from the future appear on the AR screen.

The prominent function of the iPhone in Steyerl's works produced in the first half of the 2010s insists on the materiality of the device in profilmic space as a site for unexpected manipulations and remediations. This logic of remediation exhibits what Jay David Bolter and Richard Grusin call "the twin preoccupations of contemporary media: the transparent presentation of the real and the enjoyment of the opacity of media themselves." ${ }^{4}$ In Liquidity Inc., footage of Bruce Lee is grafted onto an iPhone lockscreen while the audio track of the installation dubs the exhortation to "be shapeless, formless, like water." How Not to Be Seen appropriates the gestural logic of the touchscreen, as Steyerl demonstrates in "Lesson II" how "to scroll, to wipe, to erase, to shrink" text as it appears on screen. ${ }^{5}$ The indication is that even when we cannot see a smartphone in profilmic space, the way we engage with its interface informs the gestural repertoire of the artist performing.

Later in "Lesson III" Steyerl uses an iPhone to take a picture, holding the device in front of her face to cover her eyes, a gesture that reprises the static pose which dominates Abstract. A fig-leaf and authorial contrivance, the iPhone brings attention to the face of the artist, only partially obscured, as an emblem of the ambivalence of (in)visibility. The smartphone, like devices such as a television screen in Strike (2010), a DVD player in In Free Fall (2010), and a MacBook in Factory of the Sun (2014), are avowed as objects caught up in unstable processes of materialisation and disintegration. These artefacts provide the material support for evanescent images but are also vulnerable to breakdown or "strikes" that foreground their inoperability. By breaking down, these objects surrender their claims to support transparent, user-friendly interfaces and assume agency in their unworkability. ${ }^{6}$

I read the smartphone in Steyerl's video works as both object and tool of media archaeological enquiry: an artefact that persists in its obdurate materiality and simultaneously 
marks its own obsolescence. While Apple has released a new iPhone model at approaching a biannual rate since 2007 (a total of twenty by the year of its thirteenth anniversary in 2020), Greenfield notes a smartphone will typically yield four years' use. ${ }^{7}$ Meanwhile, the advancement of human perception of the everyday has long since become aligned to the tempo of "digital innovation", continuous optimisation, and software updates, outstripping the much slower evolutionary timescales of "social mores". ${ }^{8}$ And yet, Greenfield argues: "virtually every element of the contemporary smartphone interface paradigm derives from the first model that featured it, the original Apple iPhone of summer 2007." 9 The smartphone, and specifically the iPhone, is therefore both serial and singular: serial in its multiple iterations and continuous development of software and hardware, but singular in its underlying radical reconfiguration of our perception and navigation of daily life. For Steyerl, seriality and singularity figure as an analogue of the "signature" presence of the auteur, a singular authorial inscription that appears in many of Steyerl's works at the same time as serially reproducing her facial image across channels and through screens.

The "field" of media archaeology also implies how Steyerl adopts the tool of the smartphone as a means of "crisis management", in the terms Thomas Elsaesser elaborates in his account of "media archaeology as symptom". ${ }^{10}$ Elsaesser articulates a contemporary condition defined by "the crisis in history and causality, which has amplified into a crisis in memory and recall, reflected in turn in the crisis of narrative and storytelling." 11 (Original emphasis). In The Migrant Image: The Art and Politics of Documentary during Global Crisis, T.J. Demos similarly refers to the context of Steyerl's "traveling images" as a condition of "crisis globalisation": "our time of disaster and emergency [...] has placed post-Enlightenment paradigms of truth in crisis, and in turn brought new investments in the potential political usevalue of the documentary since the 1970 s." 12 These critical questions of history, memory and causality are central to Abstract, which sees Steyerl return to the thematic arc and forensic site 
of her friend Andrea Wolf's alleged murder in 1998, familiar from the earlier essay films November (2004) and Lovely Andrea (2007).

Abstract follows the investigation of a mountainside in Eastern Turkey, the site of a mass grave containing the remains of around forty members of the Kurdistan Workers' Party (PKK) extrajudicially killed alongside Andrea. ${ }^{13}$ The footage shot with a video camera is ostensibly replayed using an iPhone back in Germany, juxtaposing images from the investigation in "Kurdistan" with footage of Steyerl in Berlin by cutting across the work's two video channels: "shot" and "countershot". The remediation of video playback on the smartphone and the pretence of following the oppositional "grammar" of cinematic montage generates a productive anachronism in which the iPhone becomes integral to the forensic enquiry performed. The smartphone reminds the viewer of the absence - and obsolescence - of an indexical link between image and representation in video and digital images, while also illuminating its means of distributing these images ever more widely through embedded and entangled networks. The functional ambivalence of a communications network with recording built in operates as a nexus of image capture and playback in which images are created, accessed, and circulated interchangeably.

Steyerl appears in the centre of Berlin in a medium close-up in the left-hand frame, holding an iPhone with the index finger and thumb of each hand as though she is looking at the screen in landscape orientation. The right-hand frame uses intertitles to designate: "This is a countershot". Her eyes and part of her face are covered by the back of the phone. This gesture is reprised in Lesson III of How Not To Be Seen and has been likened by Ryan Conrath to a censorship bar and the conventions of eye-line matching in continuity editing. ${ }^{14}$ The blocking of the eye-line also recalls the pixelation of faces in Lovely Andrea and produces the obverse image of the balaclava-wearing protagonists in Liquidity Inc. As a result, we cannot see exactly where Steyerl is looking: the field of vision of a "one-eyed and immobile spectator" constructed 
by the vanishing point of linear perspective is denied by the phone's position, simultaneously affording Steyerl the possibility of looking elsewhere. ${ }^{15}$ Since we can only see the back of the iPhone and are thus denied sight of Steyerl's eye-line, there is a deliberate, constructive ambiguity as to whether she is recording or viewing content on the device. Steyerl figures as auteur and viewer at the same time, recalling Kaja Silverman's concept of the "author-asreceiver" in her reading of Jean-Luc Godard's self-portraits. ${ }^{16}$ The prominence of the smartphone in Abstract emphasises this ambivalent function of the "author-as-receiver" and transposes the simultaneously singular and serial qualities of the iPhone to the face of the auteur.

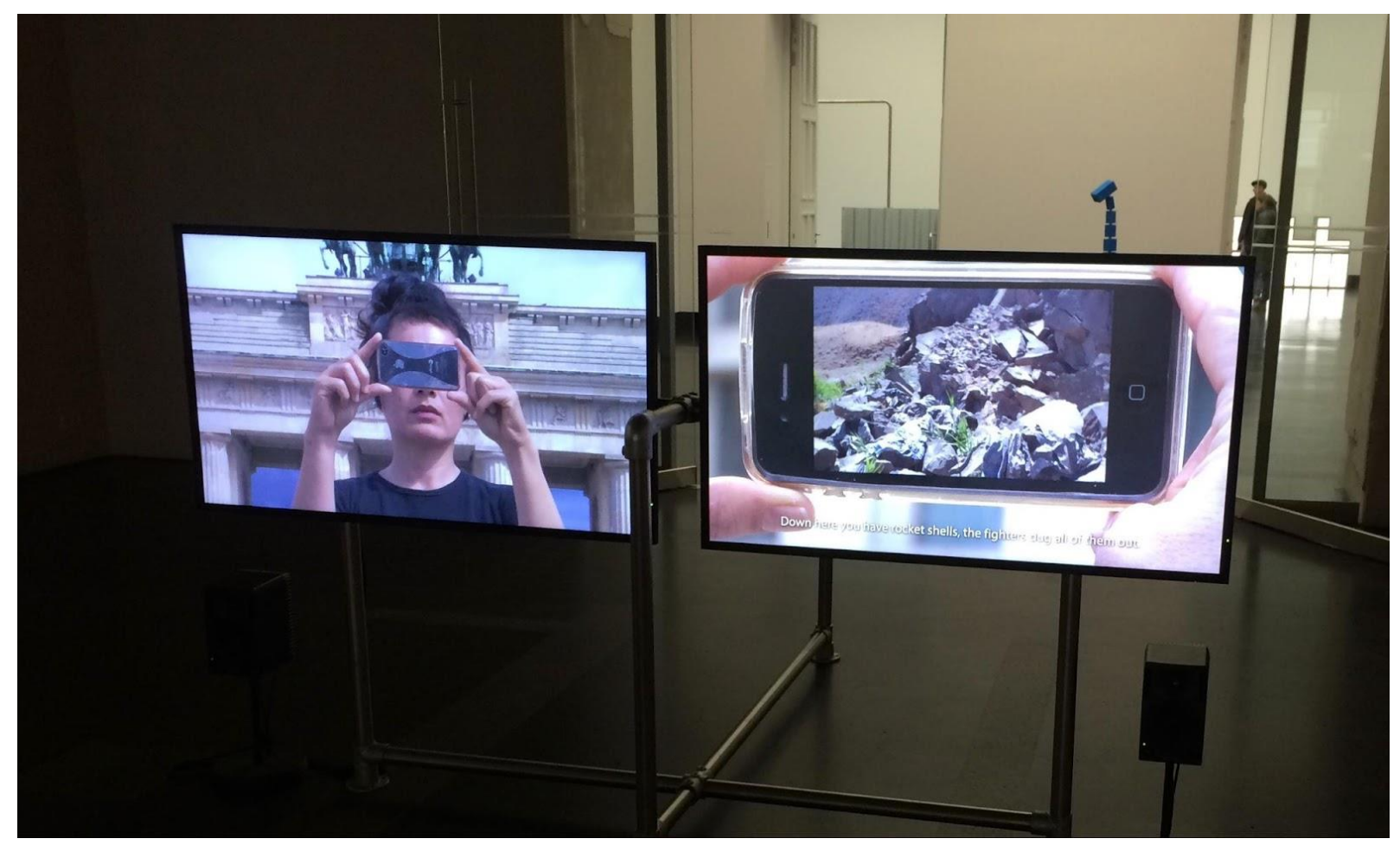

Figure 1: The iPhone as plane and window: Berlin and "Kurdistan". Exhibition view of Abstract from the Käthe-Kollwitz-Preis 2019, Akademie der Künste, Berlin. Image taken using the author's iPhone.

\section{Smartphone as Picture Postcard and Living Action}

Behind Steyerl, the photographic set-piece of the Brandenburg Gate is partially visible but instantly recognisable. The symmetrical architecture of the monument frames Steyerl's face at its centre, while the back of the iPhone is framed by a pair of hands. This configuration 
creates a frame populated by an assemblage of opaque planes as the technological, the organic, and the architectural are layered against each other from a frontal perspective. This frontal, planar "flatness" presents a stark contrast to the images from the "Kurdistan" region that show the three-dimensional space of the mountainside landscape where Andrea was allegedly murdered. Steyerl is shown the scene of the war crime by a local guide, turning over charred debris that includes clothing, cooking utensils, fired ammunition, and "many fragments of human bone."17

For a moment, we might think that Steyerl is following the touristic cliché of taking a selfie in Pariser Platz using her smartphone's reverse camera, but the orientation of her iPhone is in landscape rather than portrait. The gestural intimation of this binary, reversible orientation tells us what to expect in the smartphone's field of vision: if she were taking a photograph or video of what is in front of her, we would see a shot of Berlin's Unter den Linden boulevard. The square in front of the Brandenburg Gate, Pariser Platz, marks a space that is at once national and cosmopolitan, figuring as a metonym for Berlin's and Germany's geopolitical significance, subsequent division, and reunification in the second half of the twentieth century. This shot also revisits a site from Steyerl's The Empty Centre (1998), which traces the topography of the Brandenburg Gate and its surroundings as a symbol of imperial and colonial power from the Enlightenment to the turn of the twenty-first century. As the voiceover intones: "During [the $19^{\text {th }}$ century Gründerzeit period], plans for new buildings are developed. They are to be the face of the nation." 18

Steyerl stands statuesque, more pose than gesture, ostensibly fixed in a moment of near stasis, not unlike the figures trapped in the three-dimensional reality of Google Streetview. Has she fallen to earth like an avatar dropped in front of this landmark, the "groundless ground" to which she attempts to orient herself in the essay "In Free Fall: A Thought Experiment on Vertical Perspective"? Steyerl's essay-cum-thought-experiment describes this state of free fall, 
or groundlessness, as "the departure of a stable paradigm of orientation [...] in falling, the lines of the horizon shatter, twirl around, and superimpose." 19 In Abstract the same questions of linear perspective are challenged. Steyerl may be a figure that has come down to earth, but she inhabits a ground devoid of the stability that linear perspective may once have afforded. A central contention of Abstract is that the construction of linear perspective has been replaced by more complex and entangled, technologically mediated ways of being in the world. ${ }^{20}$

The smartphone and its functionality are central to this dynamic. Greenfield describes the development of a "machinic sense of place" owing to the device being equipped with an assisted GPS chip in addition to a magnetometer and three-axis microelectromechanical accelerometer: "a compass and gyroscope that together allow the device to register the bearer's location, orientation, and inclination to a very high degree of precision."21 The smartphone, conspicuously foregrounded in Abstract, acts as the "mediating artefact" par excellence that distributes subjectivity throughout interconnected networks of capital and control. ${ }^{22}$ Moreover, the three-dimensional orientation of the smartphone and its relation to abstract representations of space (two-dimensional maps) exposes the shattered horizons and condition of free-floating (dis-)orientation Steyerl discusses in her "thought experiment". She describes montage as a first step towards overcoming linear perspective, an abstraction that is based on "flat", geometrical lines that construct a vanishing point and deny the curvature of the earth. ${ }^{23}$ Referring to the Latin perspectiva ("to see through"), Steyerl notes how: "Linear perspective creates the illusion of a quasi-natural view to the 'outside,' as if the image plane was a window opening onto the 'real' world." ${ }^{24}$ In this respect, Steyerl rehearses a central premise of Bolter and Grusin's account of remediation: the remedial function of a new medium to "repurpose" or "reform" traditional media, which, they argue, "inevitably leads us to become aware of the new medium as a medium."25 
The linear, oppositional structure of shot-countershot - as fundamental an orientational binary as portrait-landscape - apparently revolving around Steyerl and her iPhone, therefore appears quaintly anachronistic. Montage, like linear perspective, is ironised by the figure of the smartphone, which has inaugurated a visual paradigm of floating or falling through representational space. Abstract thus exposes the foundational illusions of linear perspective and the concomitant claim to represent a "window" onto the world to a unified liberal subject. The iPhone brand and its name are perhaps the signature of this technologically reconfigured model of "subjecthood": the capital "I" replaced by the lowercase "i" grafted onto a composite form. The diminished subject "I" occupies a position that could easily be replaced by the medial and technological signifiers "smart", "cell" or "mobile". ${ }^{26}$ The horizontal bar of the iPhone but also "eye-phone" - that conceals Steyerl's eyes from the camera, and by extension her viewer, is an affordance that manages the conditions for recording or viewing images in general and images of the self in particular.

The centrality of the smartphone in Abstract's Berlin shots disrupts linear perspective as both representational technique and symbolic form. In their discussion of cinema as frame and window, Thomas Elsaesser and Malte Hagener outline the "technique" of linear perspective in which "the single vanishing point and the respective implications of size and scale ensure that a three-dimensional reality is reduced to a two-dimensional surface, which is organised in such a way to simulate another three-dimensional reality." 27 As we have seen, the mediating artefact of the smartphone complicates this relationship by orienting the user in multiple dimensions and directions. At the same time, the opacity of the iPhone as object in Abstract underlines the disjunction between everyday perception and the abstraction of the cinematic frame-as-window theorised by Rudolf Arnheim in Film as Art: "the effect of film is neither absolutely twodimensional nor absolutely three-dimensional, but something between. Film pictures are at once plane and solid." ${ }^{28}$ (Emphasis added). The not-so-picture-postcard backdrop - and frame 
- of the Brandenburg Gate equally resonates with Arnheim's assertion that film constructs a "partial illusion": "always at one and the same time a flat picture postcard and the scene of a living action." 29 On the one hand, the specifications of the iPhone guarantee the possibility of a three-dimensional visual field, expanding the linear dimensions of shot-countershot. On the other, the concrete solidity of the device restores the oppositional logic suggested by montage. The iPhone persists as "something between" transparency and opacity, plane and window; something the viewer is forced to look around or past, as much as simply through.

It is perhaps a "partial realism" that Steyerl seeks to approximate in Abstract, connecting multiple spatio-temporal "realities" in succession and simultaneity. The two-screen composition of Abstract further disperses perspectival attention between frames organised in space rather than time, appropriating a compositional structure akin to Harun Farocki's use of "soft montage" (also known as "cross-influence"). The smartphone acts both as material prop and just another form of framing and abstraction within the linear constraints of each video channel. The imbrication of these interrelated frames is rendered more explicit as we see the images from "Kurdistan", which had previously occupied the right-hand frame, played back on the iPhone screen in profilmic space. The use of hands and gesture by the guide in "Kurdistan" mimes the recurring deictic, demonstrative "this is" of the video's text: both as supplement to the subtitles of the guide's speech ("this is a jacket") and to the text of the intertitles ("this is a shot"). Meanwhile, as Steyerl's hands intrude into the frame of the Berlin shots, her fingertips provide something like a framing or support to the iPhone screen, but are also outside the framing of the smartphone itself. From the frontal perspective, this configuration creates a further interstitial space within a single frame just as the interstitial fabric of cinematic grammar is exposed in the movement between the two frames: shot and countershot. This grammar of shot-countershot also remains ambiguous and flexible in Steyerl's use of the two video channels. The text of "This is a countershot" - could be referring 
to itself, to the image track of the opposite channel, or to the images that will succeed it on the same channel. The deictic "this is" thus also serves to gesture towards the work's overdetermined referentiality with an ironic echo of René Magritte's "this is not (a pipe)" in the affirmative. The recurring "this is" reminds us of a cliché for thinking about referentiality guided by a paradigm of modernist abstraction. The effect is to posit an ambiguity between cross-reference (or influence) across frames and authorial self-reference.

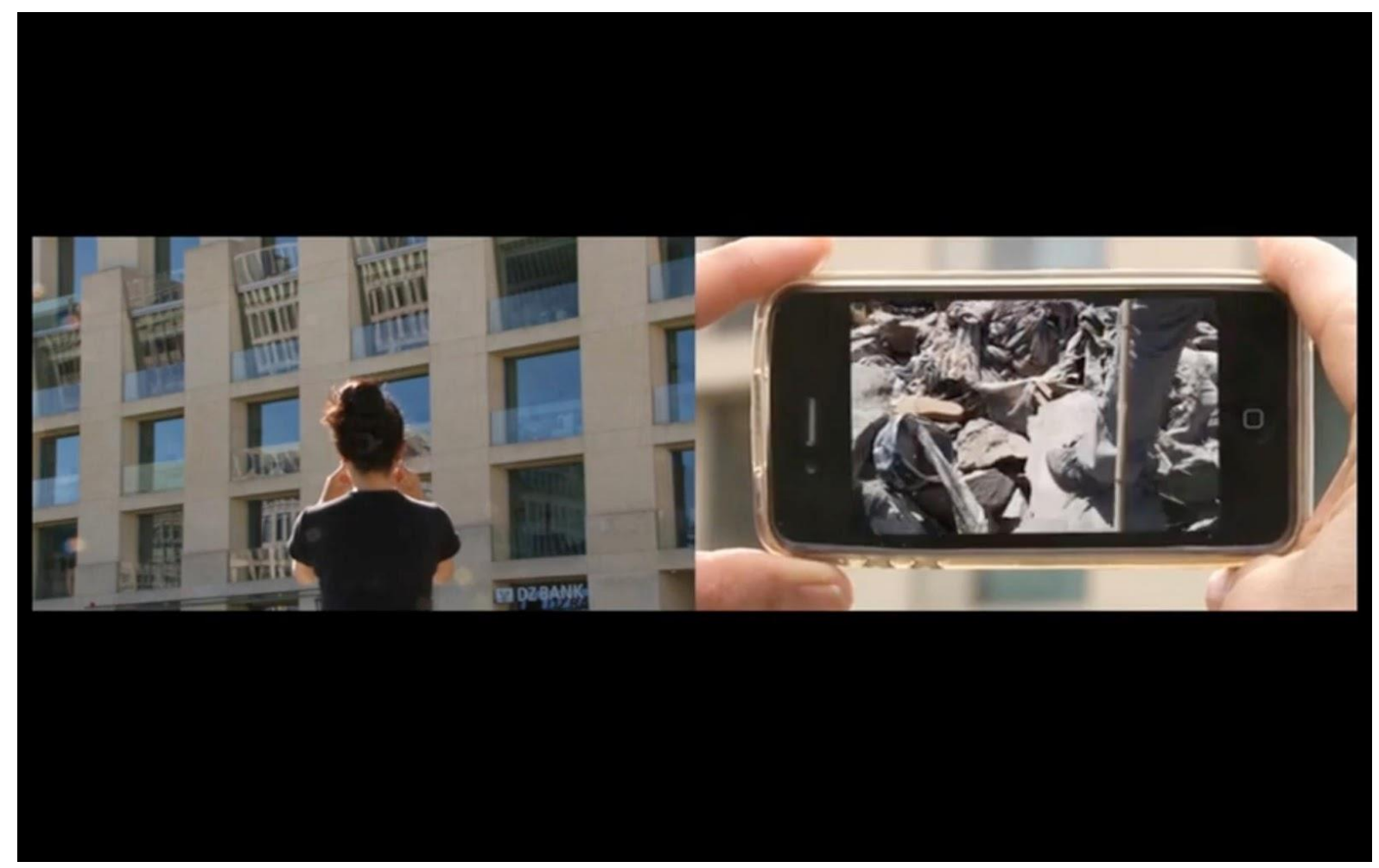

Figure 2: A telescopic mise-en-abyme reveals "Kurdistan" is in Berlin. Still from Abstract.

The side-by-side organisation of monitors ensures a further subversion of linear perspective and expands the structure of Abstract's filmic composition. In the video's fifth minute, the juxtaposition of Steyerl in front of the Brandenburg Gate (left) and the images of the Turkish mountainside replayed on the iPhone held aloft in Berlin (right) is finally succeeded by a "countershot" to the Brandenburg Gate "shot". The frontal shot of Steyerl is briefly replaced by an intertitle stating: "This is a Hellfire missile fired by Cobra helicopters." A medium shot from behind of Steyerl stood facing the DZ Bank building in Pariser Platz then appears in the left-hand frame. In the right-hand frame, the close-up of the iPhone continues to 
show footage of charred remains turned over by Steyerl's guide. As before, the interstitial space between the frame of the iPhone screen and the right-hand frame of the video channel is infringed by Steyerl's two fingers and thumbs holding the phone, an additional oblique, halfframe. In the background, a building is discernible but out-of-focus. We can infer from the corresponding shot on the left that the shot of the iPhone is taken from Steyerl's perspective. The soft montage of these shots establishes a telescopic mise-en-abyme of the shot-within-ashot (within each frame), as the relation between left and right-hand frames implies that Steyerl's head (left) would take the place of a camera recording the iPhone she holds in her hands (right). This nestling of shots binds the metonymic pair of "Berlin" and "Kurdistan" more thoroughly still: in the images of the phone screen, "Kurdistan" is in Berlin. ${ }^{30}$

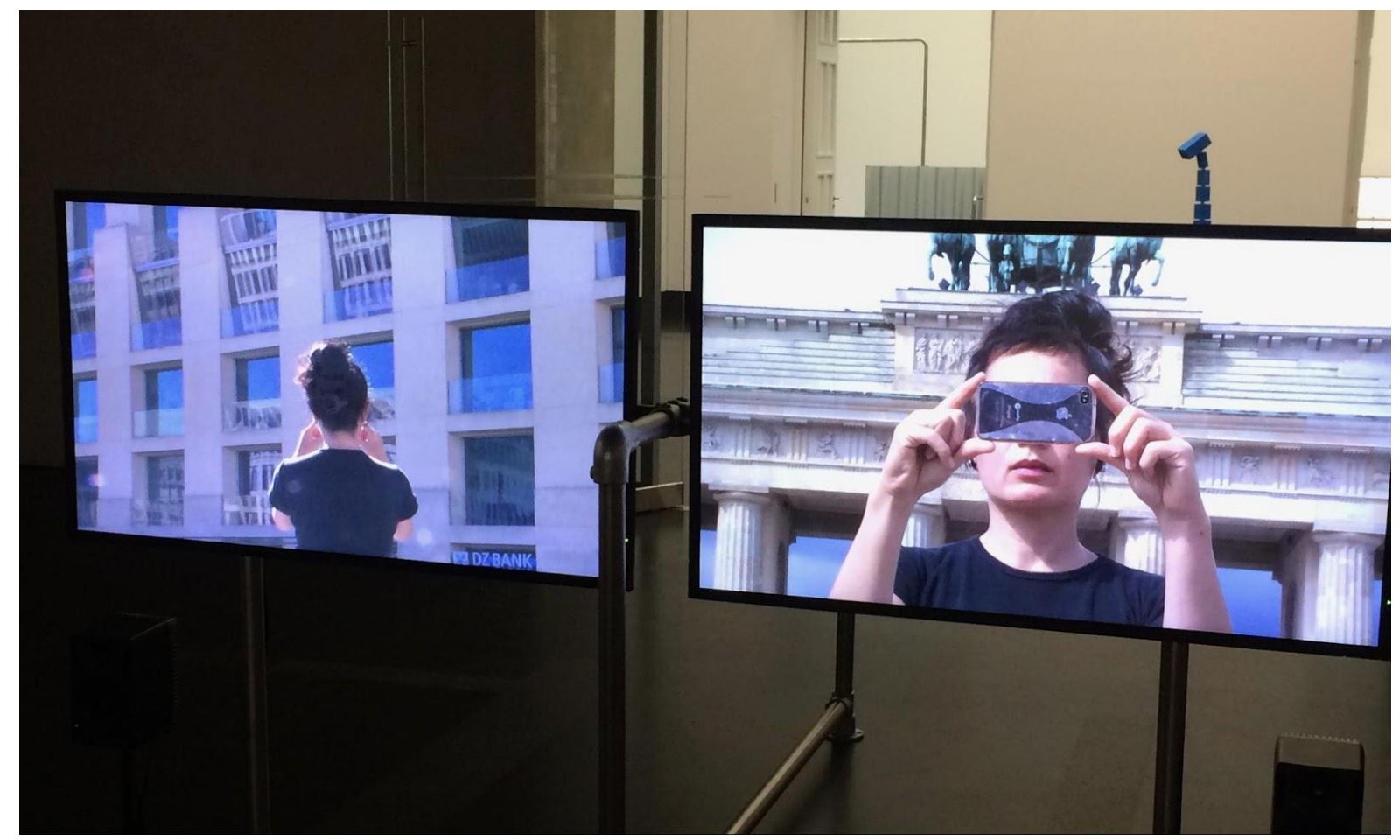

Figure 3: The line of action changes: the eventual countershot to the frontal image of Steyerl in front of the Brandenburg Gate "bends" the direction of Steyerl's gaze by about 45 degrees. Exhibition view of Abstract from the Käthe-Kollwitz-Preis 2019, Akademie. 


\section{From Abstraction to Diffraction}

Meanwhile, the footage of the battle-scarred earth shown on the iPhone blurs out of focus as the camera scans the ground for traces of the missile strike. On the left, Steyerl's hands and arms are held up in front of her, but from behind it is not possible to see what she may be holding. It is only from the shot prior to the intertitle (left) and from the corresponding shot in the right-hand frame that we can infer that she is holding the same iPhone we have been looking at from the front. The same close-up of the iPhone held in Steyerl's hands (right) is followed by the now-familiar intertitle: "This is a countershot." Both frames then turn black for several seconds before the frontal shot of Steyerl reappears in the right-hand frame. "This is a shot" returns to the left-hand frame followed by a wider shot of Steyerl from behind, affording a greater view of the DZ Bank building façade. After the shot from behind disappears from the left-hand frame, Steyerl lowers the iPhone playing the "Kurdistan" footage and the façade looms into focus. ${ }^{31}$ The "transparent" window of the iPhone screen gives way to a gallery of square windows reflecting the blue Berlin sky, inscrutable, opaque. The planar flatness of the frame is reinstated as the DZ building presents an image with no clear or stable vanishing point. An intertitle (left) follows, stating: "This is where my friend Andrea Wolf was killed in 1998." These two frames, designated as "shot" and "countershot", exploit the logic of montage as a "device for destabilising the observer's perspective and breaking down linear time", ${ }^{32}$ while also exceeding the perspectival alignment effect of the shot-countershot convention. With the eventual inclusion of the "countershot" to the "shot" of Steyerl in front of the Brandenburg Gate, the abstraction of the cinematic frame and its integration into the structure of oppositional montage gives way to a logic of diffraction.

Understood in contradistinction to reflection, both physically and philosophically, diffraction commonly describes the process by which light is made to "bend" or "spread" around a particular obstacle. ${ }^{33}$ If we assume the device and surface of the iPhone in Abstract 
act as a reflective - and reflexive - apparatus, we would expect light to bounce back in a straight line in the opposite direction. Instead, the phone functions as a "diffractive apparatus", an "obstacle" around which light disperses in circular rather than linear form. The "countershot" to the frontal shot of the Brandenburg Gate does not follow in a straight line but is in fact oriented at an angle of around 45 degrees from the previous shot. The shot following the DZ Bank façade confirms this reorientation. Steyerl is shown in close-up from the front directing her iPhone at an angle and having turned to face the building. Conrath argues for an understanding of this configuration as conventional shot-countershot since "each image depicts the same, solitary subject (Steyerl) at opposite ends of a single line of action simultaneously, conveying the impression of a 360-degree field" and "any shot that follows from one occurring on the line of action may, according to the rules of continuity editing, be taken from any angle and still maintain the impression of spatio-temporal continuity." ${ }^{34}$

But the "line of action" has changed. Steyerl has deliberately oriented herself and her (iPhone) camera towards the building that houses the headquarters of Lockheed Martin. The linear opposition between shots has been compromised, bent, or skewed, while the "rules of continuity editing" nonetheless insist that this disjuncture and diffraction be disavowed. Moreover, the 360-degree field is already established by Abstract's focus on the smartphone and the basic functionality of its reverse camera and orientation in three dimensions, something Conrath acknowledges: "it is as if we find ourselves in some ultimate stage of expanded cinema, where all the world's a shot." ${ }^{35}$ Diffraction thus serves as an extended metaphor for an altered visual paradigm that Steyerl begins to sketch in "In Free Fall": a network of multiple, dispersed gazes and perspectives. 


\section{Smartphone as Diffractive Apparatus}

The model of diffraction might cause us to look again at the use of the smartphone in Abstract to block Steyerl's face, an opaque object from one side, but also a "window" onto a site of traumatic memory from another. Steyerl's treatment of opacity - and the opacity of the smartphone in particular - establishes a mode of scepticism, a degree of circumspection, with which we might also regard transparency. The pointing (and "shooting") of the smartphone performs a gestural diffraction that redirects the linear perspective we expect to see leading from the Brandenburg Gate up Unter den Linden. Instead, the gaze is turned obliquely or aslant, away from the vanishing point of perspectivism and towards the faceless façade of the Lockheed Martin headquarters, while still purporting to maintain the binary structure of shotcountershot. Abstract presents a manifesto - an abstract - for an expanded optical regime that embraces multiple modes of looking and returning fire - executing one and many "countershots".

For theorists such as Karen Barad, diffraction betokens a philosophical paradigm that marks a departure from reflection and reflexivity which centre geometric optics: "whereas the metaphor of reflection reflects the themes of mirroring and sameness, diffraction is marked by patterns of difference." 36 This paradigmatic shift implied by diffraction as phenomenon and symbolic form suggests a further explosion of the horizons of linear perspective that Steyerl characterises as the state of "free fall". The perspectival linearity of reflection and reflexivity constructs the imaginary subject of liberal theory as the corollary of the topographical layout of the victory gate and the axes it commands: "the central viewpoint, the position of mastery, control, and subjecthood." ${ }^{37}$ By contrast, a diffractive model suggests a multiplication and dispersal of gazes and viewpoints across space, time, and matter. This diffracted trajectory is also traced by Greenfield, who contends that the autonomous subject enshrined in liberal theory is banished by the ubiquity of smartphones, with which "we're both here and somewhere else 
at the same time, joined to everything at once yet never fully anywhere at all." 38 The interaction of user and device figures as a kind of quantum experience of entanglement and interference between the human and the technological in which "our very selfhood is smeared out across a global mesh of nodes and links." ${ }^{39}$ Steyerl exploits this distribution of subjectivity by the "network organ" of the smartphone to connect two sites of indeterminacy: Andrea was killed both in "Berlin" and in "Kurdistan". ${ }^{40}$

While it is not possible here to explore fully the new materialist implications of Steyerl's investment in the (meta-)physical and metaphorical potential of quantum physics, the model of diffraction is nonetheless instructive in my reading of $A$ sstract.$^{41}$ Barad's model of "agential realism" suggests a means of understanding the motivations behind Steyerl's artistic practice and theoretical writings in terms of a "posthumanist performativity", ${ }^{2}$ which Barad characterises as the call:

to acknowledge nature, the body, and materiality in the fullness of their becoming without resorting to the optics of transparency or opacity, the geometries of absolute exteriority or interiority, and the theorisation of the human as either pure cause or pure effect while at the same time remaining resolutely accountable for the role "we" play in the intertwined practices of knowing and becoming. ${ }^{43}$ (Emphasis added).

In addition to these binaries, the smartphone connects open and closed systems and the on/off binary of digital communication that intersect in the device's basic functionality. ${ }^{44}$ The smartphone's software and hardware, its material and symbolic functions, oscillate between obstacle and window. From this "perspective", we might read the iPhone figured not as opaque or transparent but something between: a porous, diffractive "apparatus".

Thinking of Steyerl's iPhone in terms of diffraction foregrounds the smartphone technology's radical ambivalence: a network - or meshwork - of vastly dispersed sites of capture in the service of opaque corporate and state structures. At the same time, this model provides ways to think through complex interrelations and produce multiple forms of 
spectatorship and subjectivity: looks askance that reveal the complex circularity of contemporary arms, art, and image economies. By exposing the circuitous instability of these interlocking systems, Steyerl hopes to open up sites of resistance and remembrance: "if we accept the multiplication and delinearisation of horizons and perspectives, the new tools of vision may also serve to express, and even alter, the contemporary conditions of disruption and disorientation." 45 And what "tool of vision" more preeminent in the contemporary moment of "crisis globalisation" than the smartphone?

For Steyerl, multiple-channel video installation functions as a further modality of the expanded and dispersed field of vision provided by the smartphone. Conditions of moving image exhibition are invested with hopes of forming multiple models of spectatorship and "ever-new articulations of the crowd." 46 In Abstract, Steyerl from either side of her iPhone, as author and receiver, performer and viewer, looking here and elsewhere, anywhere and nowhere, performs such a rearticulation and multiplication of modes of looking. One and many Steyerls, singular and serial, pivot around the serial and singular device of the smartphone.

This constellation of gazes is dispersed further still in the use of soft montage across video channels. The abstract grammar of cinematic montage is thus extended over frames and screens, connecting complex forms of relationality between images and texts, times and spaces. The movement of Western script from left to right is exploited in Steyerl's use of intertitles, as text follows a linear trajectory from one frame to another: a processional, side-to-side movement that exceeds the conventional bounds of the frame while also encouraging the viewer to circle back between right and left frames. This organisational logic is both contained by and exceeds the geometric space of the frame and the screen: in the interference between left and right frames, and by the deliberate attention paid to the frame of the smartphone held in Steyerl's hands. The effect of this frontal mise-en-abyme, extending into or out of the image by its series of frames, is held in tension with the lateral logic that moves between the frames 
of the two-channel video work. This tension between frontal and lateral perspectives further compounds the orientational binaries of portrait and landscape, verticality and horizontality, and two and three dimensions navigated by the smartphone.

\section{Strange Loops and the Violence of Abstraction}

This inherent tension in Abstract's composition culminates towards the end of the video when Steyerl "walks out" of the right-hand frame (Berlin), proceeding diagonally past the camera that faces the Brandenburg Gate. She then appears to have walked "into" the frame of the footage shown on the smartphone in the left-hand frame ("Kurdistan") in which we see Steyerl following the guide who walks down the mountainside, descending from the site of the missile strike and Andrea's murder. The movement from right to left disrupts the spatial progression we have become used to by reading the text of Abstract's intertitles. Walking out of one frame (and off-screen) and into another (iPhone screen within a screen) confounds both the frontal logic of these various frames and their integrity as spatio-temporal units in a way that we can recognise as metaleptic: a confusion or transgression of diegetic layers as the artist moves between the "worlds" of "Berlin" and "Kurdistan". Temporal progression moves in reverse order from right to left so that Steyerl not only moves miraculously from one space to another, but also "back" in time to an "earlier" temporality, returning to the scene of the crime. 


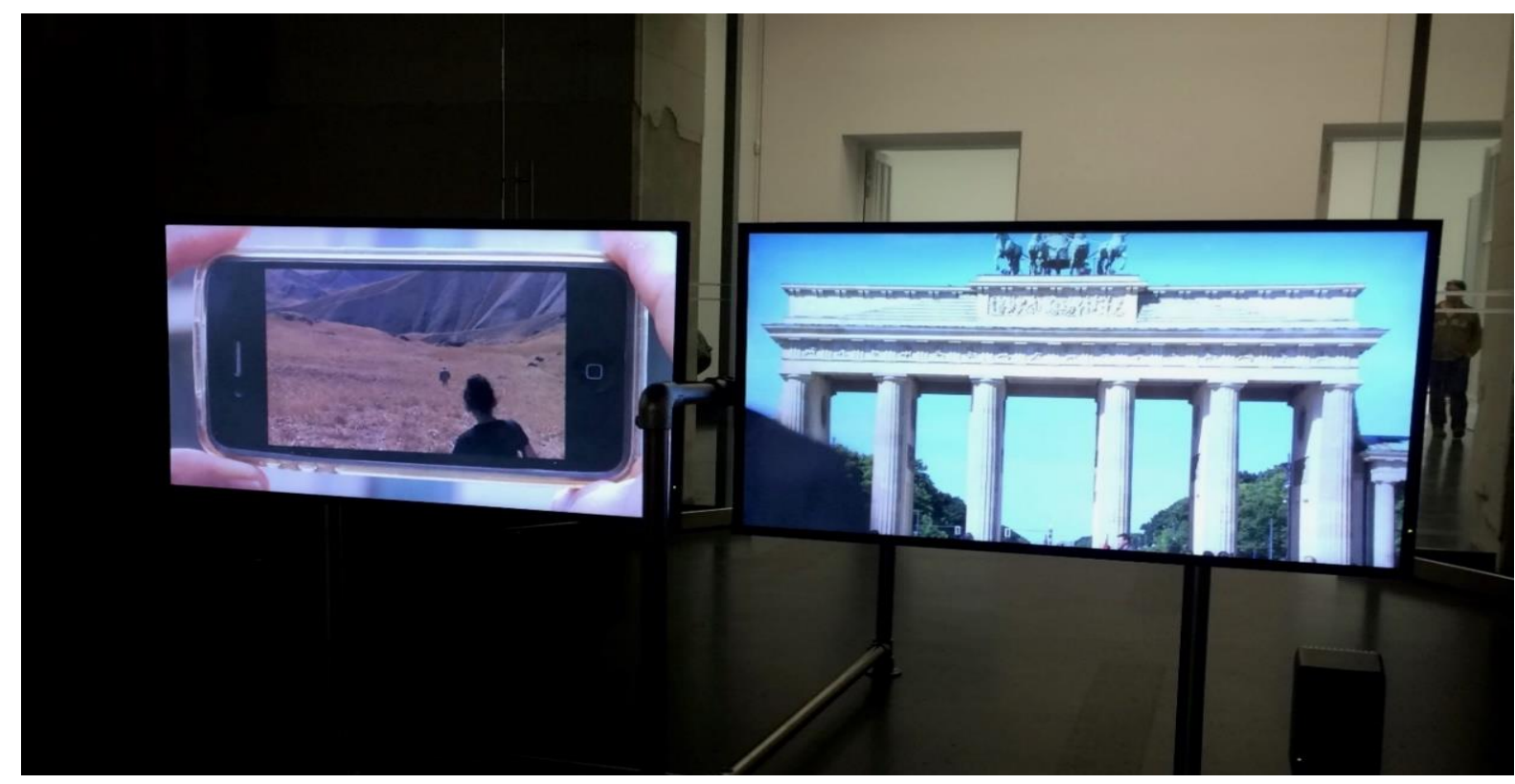

Figure 4: Steyerl departs the picture-postcard backdrop of the Brandenburg Gate and walks into the living action of the mountainside in "Kurdistan". Exhibition view of Abstract from the KätheKollwitz-Preis 2019, Akademie der Künste, Berlin.

This final part of the video is also the only time Steyerl (shot from the front in Berlin) lowers the iPhone so that we can see her face, briefly, as she walks from one frame to the other. Leaving the background of the Brandenburg Gate in the left-hand frame behind her, in Arnheim's terms, she walks from "picture postcard" to "living action". The "unveiling" of the artist, somewhat bathetic, precedes the "trick" that confirms the contrivance of the staged encounter that Abstract dramatises, as abstraction gives way to a kind of attraction. It is this metaleptic - or quantum - leap from one frame to another that typifies the shift from linear movement to strange loops performed by Steyerl in Abstract. The movement between two indeterminate spatio-temporalities suggests the transgression of a binary, oppositional form of artistic composition (shot-countershot) in favour of a different form of "conflictual aesthetics": what Oliver Marchart describes as the imperative "to see where the hidden lines of latent conflicts run, $[\ldots]$ to try to (re)activate them by reenacting their future reenactment. You'll have to construct a time loop." 47 


\section{The Inclusion of the Personal (Is Political)}

In this light, Steyerl's deliberate muddling of disparate spatio-temporal sites to the point of indeterminacy reinforces the political urgency of her artistic practice. Both the ambiguity of her indictment: "This is where my friend Andrea Wolf was killed in 1998", as the image track shows the windows of the Lockheed Martin headquarters before the intertitle is succeeded by further footage from "Kurdistan", and her "inclusion of the personal" to relate the story of Andrea's death prompt questions of where her work stands in relation to practices of "critical fabulation". Her subversion and complication of shot-countershot and other representational binaries evoke less the "grammar of battle" than a subjunctive or speculative mood, expressing "doubts, wishes, and possibilities," what could have been or might yet be rather than simply what was. ${ }^{48}$ In its grammatical manipulations, Abstract confronts the temporality of a past still enmeshed with the present, using the ever-present mediating artefact of the smartphone to open up what Lisa Lowe refers to as "a space of productive attention to the scene of loss, a thinking with twofold attention that seeks to encompass at once the positive objects and methods of history and social science and the matters absent, entangled and unavailable by its methods." 49

While it must be stressed that the object of Steyerl's practice in Abstract is not the irreparable and irreconcilable anti-black violence to which Hartman and Lowe are responding, the "state-sanctioned, extra-legal killing" of Andrea implies a certain amount of common ground between the mourning that characterises Abstract and the logic that underpins practices of critical fabulation. ${ }^{50}$ The "twofold attention" of Abstract might be seen as an unstable, ambiguous relation between the evidential claims of the intertextual "this is" and the images that necessarily elude and exceed these statements. Steyerl's adoption of an (auto)biographical mode in her films that deal with her friendship with Andrea thus adheres to the framework of bearing witness to a death that has not been recognised or recorded by state authority. 
The "inclusion of the personal", according to Saidiya Hartman, "is not a personal story that folds onto itself; it's not about navel gazing, it's really about trying to look at historical and social process and one's own formation as a window onto social and historical processes, as an example of them." ${ }^{\prime 1}$ (Emphasis added). As in Steyerl's wider oeuvre, here the personal is political, to borrow an earlier claim of radical feminist theory and praxis. ${ }^{52}$ The last set of intertitles in Abstract, "Shot. Countershot. / One opens a door to the other" enacts such an "opening out" of the personal onto the historical, the social, and the political. Hartman also conceives of the political necessity of including the personal as a strategy "to tell a story capable of engaging and countering the violence of abstraction." ${ }^{53}$ In Abstract, then, the most personal and ubiquitous of devices, the iPhone, is mobilised to serve this exemplary function. The smartphone, held in outstretched hands, reminds us of the inadequacy, illusion, and abstraction of the deictic "this is", while providing a single - and singular - example of the multiple, abstract, and opaque forms of violence that abound in the embedded meshworks of military and corporate power.

\section{Conclusion}

The iPhone features in Abstract at the centre of an aesthetic and political practice seeking to explore conflictual configurations that exceed the linear constraints of perspectivism and liberal subjecthood. The mediation between incompossible sites - spaces and times, image and text - becomes integral to this project. This mediating artefact works to negotiate and transgress a series of orientational, perceptual, and ontological binaries - and boundaries - simultaneously reinforced and revised by the smartphone. Steyerl's wielding of the iPhone in Abstract encourages a mode of scepticism that treats transparency with circumspection and makes a virtue of opacity, encouraging ways of looking obliquely, askance. To consider this mode of looking as a diffractive optics opens up a visual paradigm that allows the conventions of linear 
perspective to bend, spread and disperse through obstacles and exposes and exploits the reflective and reflexive illusions of opening a window onto the world. Steyerl retrains her multiple spectators to not only look through but around - the iPhone and the Brandenburg Gate - to view the killing field of Kurdistan in relay with Berlin's corporate architectures of arms and finance.

The central prop in Abstract, the iPhone, sits in between and moves across so many of these binaries and boundaries. It is both plane and window, picture postcard and living action, frame and screen, transparent and opaque. Its diffractive logic supports an extended metaphor of looping circularity that figures as a symbolic form to succeed linear perspective. This state of being in between further heralds the radical reorientation of everyday perception and navigation that characterises the experience of the smartphone user. In Abstract, Steyerl as iPhone user, both artist and performer, author and receiver, generates a constructive ambiguity between states of indeterminacy. This muddling of spatio-temporal realities, circulating attention between screens and within frames, opens the possibility of multiple and expanded modes of spectatorship and attunement to the complexity of contemporary circuits of capital, violence, and art, never more than a swipe or tap away from our smartphone screens. This dispersal of attention can nonetheless still present the possibility of resistance - and remembrance - following a conflictual paradigm that enlists the basic functionality of the smartphone to circle between sites of indeterminacy, mediate in-between states, and join incompossible times and places. Paradoxically, it is by establishing circuits of intensity that loop in space and time, subverting the linear constraints of perspectivism and reflective optics, that Steyerl is able to point her smartphone in a "straight line" from "Berlin" to "Kurdistan" and back again. 


\section{Notes}

${ }^{1}$ Adam Greenfield, Radical Technologies: The Design of Everyday Life (London New York: Verso, 2018), 9.

2 Throughout her oeuvre, Steyerl simply calls this location "Kurdistan". In the performance lecture Is the Museum a Battlefield? (2013), which elaborates on the central concerns of Abstract, she refers to a mountain region south of the Turkish city of Van: a "very average battlefield." References to "Kurdistan" in this article either quote Steyerl's usage or refer to the aforementioned site in Eastern Turkey.

${ }^{3}$ Greenfield, Radical Technologies, 9.

${ }^{4}$ Jay David Bolter and Richard Grusin, Remediation: Understanding New Media, (Cambridge, Mass.: MIT Press, 2003), 21.

${ }^{5}$ These gestures correspond to what Greenfield describes as a "universal, industry-wide language of touch", now common to all smartphones consisting of "the familiar tap, swipe, drag, pinch and spread." Greenfield, Radical Technologies, 321, 15.

${ }^{6}$ See "The Unworkable Interface," in Alexander R. Galloway, The Interface Effect (Cambridge, UK; Malden, MA: Polity, 2012), 25-53.

${ }^{7}$ Greenfield, Radical Technologies, 17. The environmental toll of smartphone production and supply chains adds a further poignant resonance to the juxtaposition of the iPhone and the site of excavation in Abstract.

${ }^{8}$ Ibid, $13-14$.

${ }^{9}$ Ibid, 15.

${ }^{10}$ Thomas Elsaesser, "Media Archaeology as Symptom," New Review of Film and Television Studies 14, no. 2 (2 April 2016): 183, accessed April 15, 2021, https://doi.org/10.1080/17400309.2016.1146858.

${ }^{11} \mathrm{Ibid}, 188$.

${ }^{12}$ T. J. Demos, The Migrant Image: The Art and Politics of Documentary during Global Crisis (Durham, N.C.; London: Duke University Press, 2013), xii, xvi.

${ }^{13}$ Hito Steyerl, "Missing People: Entanglement, Superposition, and Exhumation as Sites of Indeterminacy," in The Wretched of the Screen, E-Flux Journal 6 (Berlin: Sternberg Press, 2012), 155.

${ }^{14}$ Ryan Conrath, “Disarming Montage,” Film Criticism 43, no.1 (March 2019), accessed April 15, 2021, https://doi.org/10.3998/fc.13761232.0043.106.

${ }^{15}$ Hito Steyerl, "In Free Fall: A Thought Experiment on Vertical Perspective," in The Wretched of the Screen, 18.

${ }^{16}$ Kaja Silverman, "The Author as Receiver," October 96 (Spring 2001): 17-34, accessed April 19, 2021, https://doi.org/10.2307/779115.

${ }^{17}$ Steyerl, "Missing People," 155

${ }^{18}$ Both The Empty Centre and Abstract formed part of Steyerl's Käthe Kollwitz Prize exhibition held in 2019 at Berlin's Akademie der Künste, a building adjacent to the DZ bank building in Pariser Platz with a façade in view of the Brandenburg Gate. As in Steyerl's oeuvre, art, arms, and finance sit cheek by jowl in the centre of Berlin.

${ }^{19}$ Steyerl, "In Free Fall," 14. 
${ }^{20}$ Conrath argues that Abstract demonstrates oppositional montage's obsolescence as a model for thinking cinema and warfare together: "Any paradigm figuring discretely opposed forces locked in battle, because it necessarily assumes a stable field of action, would seem to have little bearing on today's wide-ranging, de-centered, and largely instantaneous and invisible movement of deadly vectors." Conrath, "Disarming Montage."

${ }^{21}$ Greenfield, Radical Technologies, 16.

${ }^{22}$ This is not only the case for the scenes that feature the smartphone most prominently in a capital city of the Global North, but also for the footage shot in Eastern Turkey. Steyerl claims in Is the Museum a Battlefield? that she received "spam" by email sent to her phone from "neoliberal art institutions" at the moment the "Kurdistan" images were captured.

${ }^{23}$ Steyerl, "In Free Fall," 18.

${ }^{24}$ Ibid.

${ }^{25}$ Bolter and Grusin, Remediation, 19. See also Anne Friedberg, The Virtual Window: From Alberti to Microsoft, (Cambridge, Mass.: MIT Press, 2009).

${ }^{26}$ According to Apple founder Steve Jobs the "i" first introduced with the "iMac" in 1998, had five potential "meanings": "internet, individual, instruct, inform, [and] inspire." Andrew Griffin, “iPhone: What The 'I' in Apple's Handset Name Stands For,” The Independent, Feburary 18, 2016, accessed April 19, 2021, https://www.independent.co.uk/lifestyle/gadgets-and-tech/news/iphone-apple-name-imac-i-internet-phone-handseta6881701.html.

${ }^{27}$ Thomas Elsaesser and Malte Hagener, Film Theory: An Introduction through the Senses, $2^{\text {nd }}$ ed. (New York: Routledge, 2015), 21.

${ }^{28}$ Rudolf Arnheim, Film as Art, (Berkeley: University of California Press, 1957), 12.

${ }^{29} \mathrm{Ibid}, 26$.

${ }^{30}$ Thus extending the logic of November's intertitles that state: "Kurdistan is not only there but here", before "Germany is in Kurdistan" dissolves into "Kurdistan is in Germany."

${ }^{31}$ Conrath reads this focus pulling as an additional form of montage.

${ }^{32}$ Steyerl, "In Free Fall," 22.

${ }^{33}$ Karen Barad, Meeting the Universe Halfway: Quantum Physics and the Entanglement of Matter and Meaning (Durham: Duke University Press, 2007), 80.

${ }^{34}$ Conrath, "Disarming Montage."

${ }^{35}$ Ibid.

${ }^{36}$ Barad, Meeting the Universe Halfway, 72.

${ }^{37}$ Steyerl, "In Free Fall," 21.

${ }^{38}$ Greenfield, Radical Technologies, 27.

${ }^{39}$ Ibid.

${ }^{40}$ Ibid.

${ }^{41}$ See Steyerl, "Missing People," and "Cut! Reproduction and Recombination," in The Wretched of the Screen, 138-59, 176-90.

42 That diffraction patterns can be observed in any kind of wave (water, sound, and light) implies Steyerl's attraction to elemental forms - from Liquidity Inc. to Factory of the Sun marks an investment in diffraction as both physical phenomenon and metaphor. 
${ }^{43}$ Karen Barad, "Posthumanist Performativity: Toward an Understanding of How Matter Comes to Matter," Signs 28, no. 3 (2003): 812, accessed April 19, 2021, https://doi.org/10.1086/345321.

44 "Just as the mass implementation of automatically revolving and sliding passages signals a forfeiture of the door's symbolic function (inside/outside) for a cybernetic one (on/off), so too does the doubling of the [smartphone] camera bespeak the radical reversibility of contemporary images." Conrath, "Disarming Montage."

${ }^{45}$ Steyerl, "In Free Fall," 26.

${ }^{46}$ Ibid.

${ }^{47}$ Oliver Marchart, Conflictual Aesthetics: Artistic Activism and the Public Sphere (Berlin: Sternberg Press, 2019), 181.

${ }^{48}$ Saidiya Hartman, "Venus in Two Acts," Small Axe 12, no. 2 (2008): 11, accessed April 19, 2021, muse.jhu.edu/article/241115.

${ }^{49}$ Lisa Lowe, "The Intimacies of Four Continents," in Ann Laura Stoler, ed., Haunted by Empire: Geographies of Intimacy in North American History (Durham: Duke University Press, 2006), 208.

${ }^{50}$ See Christina Sharpe's description of antiblack violence in the United States and the afterlives of transatlantic slavery: "The ongoing state-sanctioned legal and extralegal murders of Black people are normative and, for this so-called democracy, necessary; it is the ground we walk on." (emphasis added). Christina Sharpe, In the Wake: On Blackness and Being (Durham: Duke University Press, 2016), 7.

${ }^{51}$ Patricia J. Saunders, "Fugitive Dreams of Diaspora: Conversations with Saidiya Hartman," Anthurium A Caribbean Studies Journal 6, no. 1, (2008): 5, accessed April 19, 2021, http://doi.org/10.33596/anth.115.

${ }^{52}$ See Carol Hanisch, "The Personal is Political," in B. A. Crow, ed., Radical Feminism: A Documentary Reader (New York: NYU Press, 2000), 113-116.

${ }^{53}$ Saunders, "Fugitive Dreams of Diaspora," 5.

\section{Bibliography}

Arnheim, Rudolf. Film as Art. Berkeley: University of California Press, 1957.

Barad, Karen. Meeting the Universe Halfway: Quantum Physics and the Entanglement of Matter and Meaning. Durham: Duke University Press, 2007. "Posthumanist Performativity: Toward an Understanding of How Matter Comes to Matter.” Signs 28, no. 3 (2003): 801-31. Accessed April 18, 2021. https://doi.org/10.1086/345321.

Bolter, Jay David, and Richard Grusin. Remediation: Understanding New Media. Cambridge, Mass.: MIT Press, 2003.

Conrath, Ryan. "Disarming Montage." Film Criticism 43, no.1 (March 2019). Accessed April 15, 2021, https://doi.org/10.3998/fc.13761232.0043.106.

Demos, T. J. The Migrant Image: The Art and Politics of Documentary during Global 
Crisis. Durham, N.C.; London: Duke University Press, 2013.

Elsaesser, Thomas. "Media Archaeology as Symptom." New Review of Film and Television Studies 14, no.2 (2016): 181-215. Accessed April 15, 2021, https://doi.org/10.1080/17400309.2016.1146858.

Elsaesser, Thomas and Malte Hagener. Film Theory: An Introduction through the Senses, 2nd ed. New York: Routledge, 2015.

Friedberg, Anne. The Virtual Window: From Alberti to Microsoft. Cambridge, Mass.: MIT Press, 2009.

Galloway, Alexander R. The Interface Effect. Cambridge, UK; Malden, MA: Polity, 2012.

Greenfield, Adam. Radical Technologies: The Design of Everyday Life. London, New York: Verso, 2018.

Griffin, Andrew. "iPhone: What The 'I' in Apple's Handset Name Stands For." The Independent. Feburary 18, 2016. Accessed April 19, 2021, https://www.independent.co.uk/life-style/gadgets-and-tech/news/iphone-apple-nameimac-i-internet-phone-handset-a6881701.html.

Hanisch, Carol. "The Personal is Political." in B. A. Crow, ed., Radical Feminism: A Documentary Reader. New York: NYU Press, 2000. 113-116.

Hartman, Saidiya. "Venus in Two Acts.' Small Axe 12, no. 2 (2008): 1-14. Accessed April 19, 2021, muse.jhu.edu/article/241115.

Lowe, Lisa. "The Intimacies of Four Continents." in Ann Laura Stoler, ed., Haunted by Empire: Geographies of Intimacy in North American History. Durham: Duke University Press, 2006. 191-212.

Marchart, Oliver. Conflictual Aesthetics: Artistic Activism and the Public Sphere. Berlin: Sternberg Press, 2019.

Saunders, Patricia J. "Fugitive Dreams of Diaspora: Conversations with Saidiya Hartman." Anthurium A Caribbean Studies Journal 6, no. 1, (2008): 1-16. Accessed April 19, 2021, http://doi.org/10.33596/anth.115.

Sharpe, Christina Elizabeth. In the Wake: On Blackness and Being. Durham: Duke University Press, 2016.

Silverman, Kaja. “The Author as Receiver.” October 96 (2001): 17-34. Accessed April 22, 2021, https://doi.org/10.2307/779115.

Steyerl, Hito. The Wretched of the Screen. E-Flux Journal 6. Berlin: Sternberg Press, 2012.

\section{Filmography}

Steyerl, Hito. Power Plants. 2019. HD video and Augmented Reality installation. 
Factory of the Sun. 2014. HD video installation.

—. Liquidity Inc. 2014. HD video installation.

—. Is the Museum A Battlefield?. 2013. Lecture recording and HD video.

- How Not To Be Seen: A Fucking Didactic Educational .MOV File. 2013. HD video.

- Abstract. 2012. Two-channel HD video.

- In Free Fall. 2010. HD video.

- Strike. 2010. HD video.

- Lovely Andrea. 2007. SD video.

- November. 2004. Transferred $16 \mathrm{~mm}$ film.

_. Die leere Mitte (The Empty Center). 1998. 16mm film.

\section{Author Biography}

Lawrence Alexander is a third-year PhD candidate at the University of Cambridge's Centre for Film and Screen. His research focuses on the theme of "face value" in the moving image practices of Harun Farocki, Hito Steyerl and William Kentridge. His doctoral dissertation adopts the Deleuzo-Guattarian model of "faciality" as a framework to consider these artists' engagement with late capitalist and colonialist structures of power and control, as well as questions of individual and cultural memory in dialogue with media-archaeological, postcolonial, and critical race theoretical perspectives on moving image scholarship. He is the recipient of a studentship jointly hosted by the Cambridge AHRC Doctoral Training Partnership and Churchill College. 